\title{
AVALIAÇÃO DA CAVITAÇÃO NA CURVA DE LIGAÇÃO POÇO-TÚNEL DE UM VERTEDOR TIPO TULIPA.
}

\section{Bruno dos S. Marques, Laura Maria C. F. Fais.}

\section{Resumo}

Vertedores são obras hidráulicas associadas a barragens, e têm por finalidade a condução da água excedente para jusante da barragem em eventos extremos de vazão. O vertedor do tipo tulipa caracteriza-se por sua aplicabilidade em locais com limitação de espaço, pois localiza-se no interior do reservatório. Neste tipo de vertedor o escoamento desce por um poço vertical, sofre uma deflexão e segue por um túnel horizontal até o corpo hídrico a jusante da barragem. Na curva de ligação poço-túnel, onde ocorre a deflexão do escoamento, ocorrem bruscas variações de pressão. Assim, o presente trabalho tem por objetivo a análise dos índices de cavitação na comparação entre quatro geometrias distintas de curva, a partir dos dados experimentais obtidos por Fais (2007).

\section{Palavras-chave:}

Vertedor tulipa, flutuação de pressão, cavitação.

\section{Introdução}

Um vertedor tulipa, segundo Şentürk (1994), é normalmente projetado para barragens com limitações de espaço, localizando-se na área do reservatório. É composto tipicamente por quatro partes: a seção do vertedor (em formato de tulipa), o poço vertical, a curva de ligação poço-túnel e o túnel horizontal. De acordo com Fais (2007) a região crítica do escoamento é a curva de ligação, pois ali ocorrem variações bruscas de pressão devido à deflexão do escoamento, do sentido vertical para o horizontal. No estudo realizado por Fais (2007) foram analisadas as pressões ao longo de quatro curvas com geometrias distintas, e os dados experimentais obtidos no estudo supracitado foram utilizados no presente, a fim de avaliar o índice de cavitação $(\sigma)$, conforme descrito pela equação (1), definida por Falvey (1990), para diferentes tomadas de pressão ao longo das curvas.

$$
\sigma=\frac{P-P_{v}}{\rho \frac{V m^{2}}{2}}
$$

Onde $P$ é a pressão média, $P_{v}$ é a pressão de vapor, $\rho$ é a massa específica da água e $V_{m}$ é a velocidade média. Assim, este trabalho tem como objetivo avaliar a influência da flutuação de pressão na curva de ligação poço-túnel de um vertedor tipo tulipa no aparecimento da cavitação. Para isso, foram utilizados os resultados experimentais obtidos por Fais (2007), para o modelo físico do vertedor de Paraitinga - SP.

\section{Resultados e Discussão}

A partir dos dados de pressão obtidos por Fais (2007), calculou-se o índice de cavitação para diferentes situações de vazão $\left(Q / Q_{p}=0,3, Q / Q_{p}=0,6, Q / Q_{p}=0,8\right.$ e $\left.Q / Q_{p}=1,0\right)$, sendo $Q_{p}$ a vazão de projeto do vertedor. Para a análise dos resultados, destacam-se os valores calculados para a situação de vazão máxima $\left(Q / Q_{p}=1,0\right)$, obtendo-se os resultados mostrados na Tabela 1.

Analisando-se os valores dos índices de cavitação calculados, e comparando-se as curvas com geometria alternativa (C2, C3 e C4) com a curva circular C1, notase que houve, de forma geral, uma diminuição dos valores de $\sigma$ para a parte externa das curvas (tomadas 3 , 4, 5 e 6), com exceção da curva C3 na tomada 6 e C4 nas tomadas 3 e 6 . Para a parte interna das curvas (tomadas 11, 12, 13 e 14) houve uma tendência de aumento dos valores em comparação à curva $\mathrm{C} 1$, com exceção das tomadas 13 e 14 da curva $\mathrm{C} 2$ e da tomada 14 da curva C4. A tabela 2 mostra as variações percentuais dos valores calculados em comparação com a curva original $\mathrm{C} 1$.

Tabela 1. Índices de cavitação, valores adimensionais.

\begin{tabular}{|c|c|c|c|c|c|c|c|c|}
\hline \multicolumn{10}{|c|}{ Indices de cavitação (e-04) } \\
\hline Cur & \multicolumn{10}{c|}{ Tomadas } \\
\cline { 2 - 10 } vas & $\mathbf{3}$ & $\mathbf{4}$ & $\mathbf{5}$ & $\mathbf{6}$ & $\mathbf{1 1}$ & $\mathbf{1 2}$ & $\mathbf{1 3}$ & $\mathbf{1 4}$ \\
\hline C1 & $-7,17$ & $-6,59$ & $-6,79$ & $-6,82$ & $-8,65$ & $-7,92$ & $-7,79$ & $-7,85$ \\
\hline C2 & $-7,23$ & $-9,33$ & $-7,52$ & $-7,18$ & $-6,95$ & $-7,74$ & $-8,17$ & $-7,88$ \\
\hline C3 & $-7,78$ & $-7,50$ & $-7,09$ & $-6,72$ & $-6,56$ & $-7,78$ & $-7,58$ & $-7,58$ \\
\hline C4 & $-6,98$ & $-7,68$ & $-7,66$ & $-6,69$ & $-7,41$ & $-7,39$ & $-7,48$ & $-8,11$ \\
\hline
\end{tabular}

Tabela 2. Variações percentuais de $\sigma$

\begin{tabular}{|c|c|c|c|c|c|c|c|c|}
\hline \multicolumn{9}{|c|}{ Variações de $\sigma$ em comparação a C1 (\%) } \\
\hline \multirow{2}{*}{$\begin{array}{l}\text { Cur } \\
\text { vas }\end{array}$} & \multicolumn{8}{|c|}{ Tomadas } \\
\hline & 3 & 4 & 5 & 6 & 11 & 12 & 13 & 14 \\
\hline $\mathrm{C} 2$ & $\downarrow 0,8$ & $\downarrow 41,7$ & $\downarrow 10,7$ & $\downarrow 5,3$ & $\uparrow 19,6$ & $\uparrow 2,3$ & $\downarrow 4,9$ & $\downarrow 0,3$ \\
\hline $\mathrm{C} 3$ & $\downarrow 8,5$ & $\downarrow 13,9$ & $\downarrow 4,4$ & $\uparrow 1,4$ & $\uparrow 24,2$ & $\uparrow 1,8$ & $\uparrow 2,7$ & $\uparrow 3,4$ \\
\hline C4 & $\uparrow 2,7$ & $\downarrow 16,5$ & $\downarrow 12,9$ & $\uparrow 1,8$ & $\uparrow 14,3$ & $\uparrow 6,7$ & $\uparrow 4,0$ & $\downarrow 3,4$ \\
\hline
\end{tabular}

\section{Conclusões}

Dados os resultados obtidos para os valores dos índices de cavitação e sua análise comparativa, conclui-se que a alteração da geometria da curva de ligação poço-túnel dos vertedores tipo tulipa resulta na modificação dos parâmetros de cálculo importantes para o dimensionamento do mesmo. Observou-se que na parte externa das curvas, onde naturalmente ocorrem pressões com valores positivos, o índice de cavitação apresentou uma diminuição de seu valor com a modificação da geometria das curvas, enquanto na parte interna, onde há uma tendência de ocorrência de pressões negativas, houve um aumento dos valores desse parâmetro.

FAIS, L. M. C. F. Análise experimental da curva de ligação poçotúnel em vertedor com emboque tipo tulipa. [sn], 2007.

FALVEY, H. T.Cavitation in Chutes and Spillways. [S.I.]: U.S. Bureau of Reclamation, 1990.

ŞENTÜRK, F. Hydraulics of dams and reservoirs. [S.I.]: Water Resources Publication, 1994. 